\title{
Development of a Novel Approach to Enhance Water Use Efficiency in Auto- Irrigation System
}

\author{
MANJU KAUSHIK ${ }^{1 *}$, RAJEEV RATAN ${ }^{2 *}$ \\ 1. Lecturer, Department of ECE, Government Polytechnic Uttawar, Palwal, Haryana, India, 121102 \\ \# 404 Victoria-1,Omaxe Heights,Omaxe City,Palwal,Distt.-Palwal, State Haryana, India. \\ Pin - 121102. \\ Email ID:manjudixit10@gmail.com \\ 2. Associate Professor, Department of ECE, M.V.N. University,Palwal,Haryana,India121102 \\ \# 49/4, Jawahar Nagar, PalwalDistrict Palwal, State Haryana, India. \\ Pin-121102. \\ Email ID: rajeevratanarora@gmail.com
}

\begin{abstract}
As we all know that water is essential requirement for the growth of civilization and plants. From the available fresh water supply agriculture requires about $\mathbf{7 0 - 8 0 \%}$ of water. Due to increase in population and development of industries, there is a competitive demand of fresh water supply and thereforewastage of water should be reduced sustainable development of Mankind. The main purpose of our research is to develop a system which automatically monitors and modifies the environmental parameters of the plants like soil moisture, temperature, humidity etc. which can affect the growth of plants without human interference for optimization of available limited resources of nature.
\end{abstract}

The proposed system can keep an eye on various agricultural parameters and recordsthe obtained values in data logger. This real time irrigation systemscan be used to control the agricultural parameters as desired by the farmer from distant location using telemetry.

Keywords: Water Use Efficiency, Auto Irrigation System, Drip Irrigation System, soil moisture sensors, Humiditysolenoid valves.

\section{INTRODUCTION:}

Irrigation is a process of watering the plants for their proper growth and development to achieve quality and productivity. In our research work, saving of water by using it efficiently is our main aim. Water is very precious natural resource that should not be wasted. For achieving our goal, scientific scheduling is required, which gives application of right amount of water, at right time, at needed part of plant with the combination of microcontroller and sensors (Laxmi Shabadi, July 2014).

This require continuous monitoring of soil moisture content (Syed Mubarak, MAY 2015) at root zone and initiate irrigation as per pre programmed scheduling depending upon nature of plant, its growth, soil type and environment. As per the need of scientific irrigation scheduling, sensors have to be planted to at appropriate distance to each other in the soil near the root zone to access the representative moisture status. The signals originated detected by soil moisture sensors have to be processed by microcontroller for irrigation scheduling as per pre determined programme. Microcontroller should also be programmed to transmit the signal at a distant location where pumping and well mechanism (for control of irrigation) is located. Similarly output of these sensors have also be processed by the microcontroller as per pre-determine program to terminate the irrigation depending upon the plant, its stage of growth, soil and environment (H.T.Ingale, November 2012).

Smart irrigation (Drip Irrigation) is also included with microcontroller and sensors for using water efficiently which can also improve the soil fertility, soil salinity and soil quality. There is slow rate of water application in drip irrigation as the application rate is about 12/15lper hour and water is applied directly to the root zone .In this entire fields soil is not wetted.

\section{EXISTING SYSTEM:}

In existing system, there were two main disadvantages firstly, the switching of pump was manually and secondly for controlling irrigation, farmer have to travel from farm unit to home and vice versa. A lot of water is wasted in absence of power and in absence of farmer, when farmer has to go to home after waiting for power to keep the pump on. There are a lot of chances of water wastage when pump remains on and water is freely flow. In this whole phenomenon farmer has to take a lot of fatigue and panic. Due to this power and water both are also wasted and the irrigation water is not utilized efficiently and properly. 


\section{PROPOSED SYSTEM:}

The proposed system is going to be fully automated using ARM microcontroller and having drip irrigation system. In this system, a fully automated panel is set up in the farmer's sitting room. This panel include a monitoring system which is connecting to the microcontroller unit at the receiver end (sitting room) and the other micro controller unit is at the transmitter end (farms) which is going to sense the actual conditions of the crop like moisture level of the crop .This moisture level is displayed on the monitoring system of panel of sitting room as these two transmitter unit and receiver unit is connected to each other by telemetry as also shown in fig 4 and fig 5.

Hence wastage of water is controlled by this system using drip irrigation as the water application rate of dripper is $1-12 \mathrm{l} / \mathrm{hr}$ (means in $1 \mathrm{hr}$ minimum rate of water flow is $1 \mathrm{l}$ and maximum flow of water is $12 \mathrm{l}$.

So, this system covers all the disadvantages of our existing systems by using dripper with ARM Microcontroller and goal of water use efficiency is achieved.

\section{BLOCK DIAGRAM:}

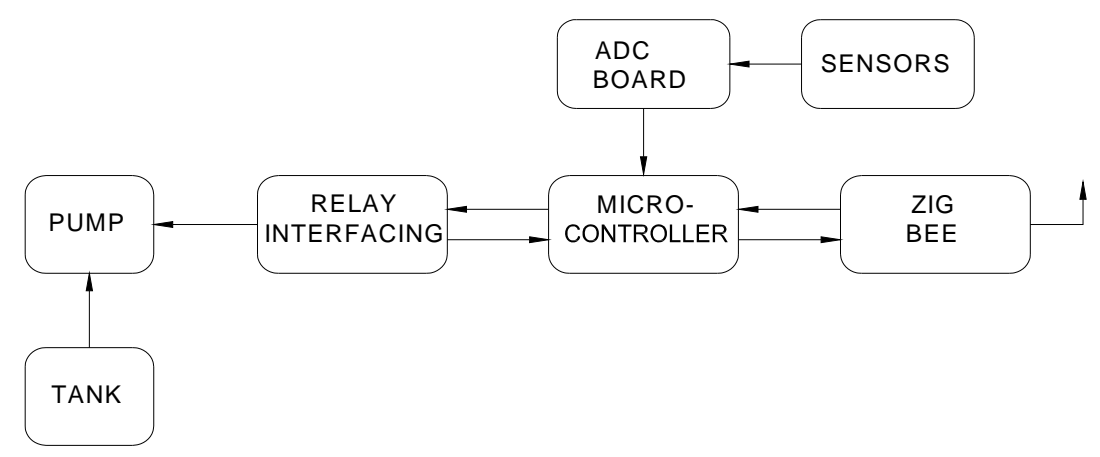

Fig 1: TRANSMITTER UNIT

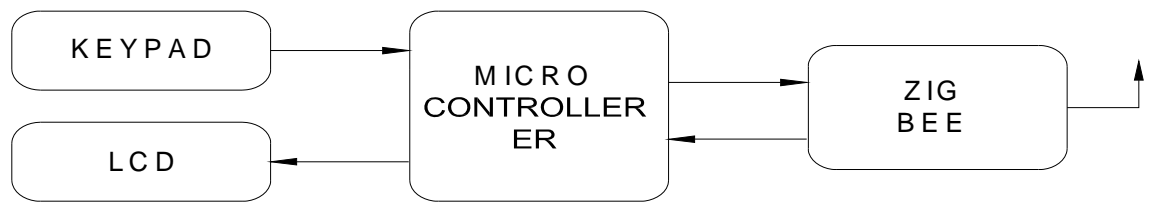

Fig 2: RECIEVER UNIT

\section{COMPARISION WITH REFERANCES:}

If we compared this paper with references then the paper is better than the others as follows:

1. This paper is the combination of ARM microcontroller with drip irrigation having soil moisture sensors and by this water is used efficiently as with dripper, water is only given at root zone and also prevent the farms with weedicides and pests, by extra flow of water as this is compared with (M.K.Bhanarkar, 2016) which gives the concept of monitoring of soil salinity and moisture with the wireless sensors and microcontroller, Our paper is adding the concept of dripper for preventing water wastage.

2. The use of ARM microcontroller which have the best application than other microcontroller just because of their tiny size, low power consumption and compiler than others make this better than others.

3. The use of dripper make the use of water very efficiently and gives the required amount of application rate as the water application rate of dripper is $1-12 \mathrm{l} / \mathrm{hr}$ (means in $1 \mathrm{hr}$ minimum rate of water flow is $1 \mathrm{l}$ and maximum flow of water is 12l).

\section{LITERATURE SURVEY:}

Fresh Water is the necessity of each and every living creature. So, it is our responsibility and our prime duty to save water .In irrigation most of the water is wasted by free flow irrigation. The water should be efficiently used in irrigation by the use of microcontroller.

The right amount of water in paddy crop with less water wastage and power by using microcontroller is AVR ATMEGA-161 microcontroller with wireless sensor using solenoid valve for making the use of water 
efficiently is given by (Fule, C. R., January 2014). The concept of fertility meter and ph meter for measuring fertility and hydronium ion concentration is given by (Rashid Hussian, March 2013) .Both these meters are help to take care of moisture content and fertility of soil and hence prevent the excessive water usage and rapid growth of weeds. The concept of rain gun is added by (R.suresh, February 2014) for raining the nitrogen mix water in crop and hence this will help in increasing the nutritive value of soil. (Waykole, 2012)Uses the concept of combination of zig- bee, wireless sensors and microcontroller unit for the efficient use of water. (Kolhe, June 2012)uses ARM7 microcontroller and also added the concept of controlling of light, heater, fan and other with microcontroller in green house system according to the environment condition. (B.VidyaSagar, May 2012 )using GSM for automation in green house and having microcontroller with a set of sensors to control the soil condition and environment condition according to the required condition. (Y.R.Dhumal, May 2013) uses zig bee and smart phone with microcontroller to make the system automatic for controlling the various parameters like humidity, moisture, temperature are monitored by sensors and reading is to be transmitted by zig bee in receiver section and controlled by micro controller (Dondapati, (August 2012)) uses multisensors for keep an eye on the whole field. It demonstrate the effectiveness of sensors which help the project to be automated to yield more effectiveness in farming and overcome the effect caused by disadvantages in normal farming without any human interference. (A.Rhman, 2014)give wirelessly controlled irrigation system in this they explain how the wireless sensors are connected to Zig-bee pro module for controlling the irrigation. There are two modes in this proposed system, these are smart mode and manual mode according to the condition of irrigation. (Bankar, April - June 2016)uses the concept of fertigation system along with water pumping system

\section{FLOW CHART}

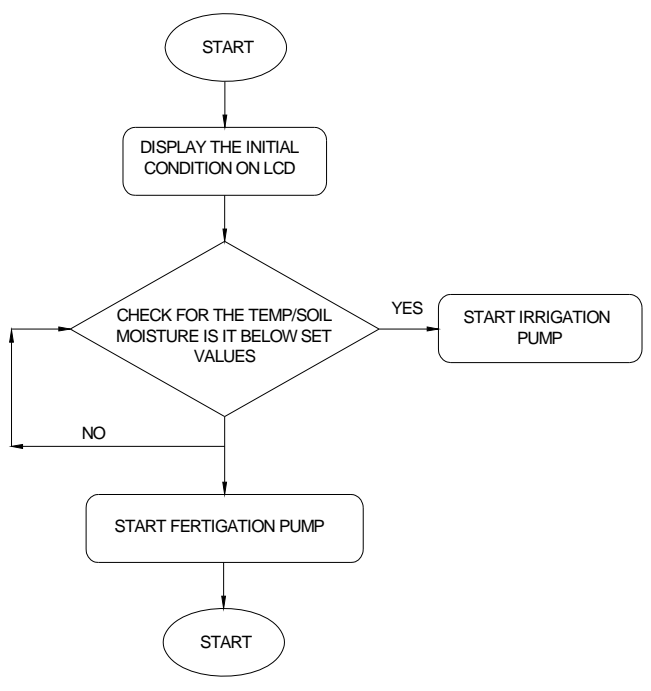

Fig 3 : Flow Chart of the system

RESULT:

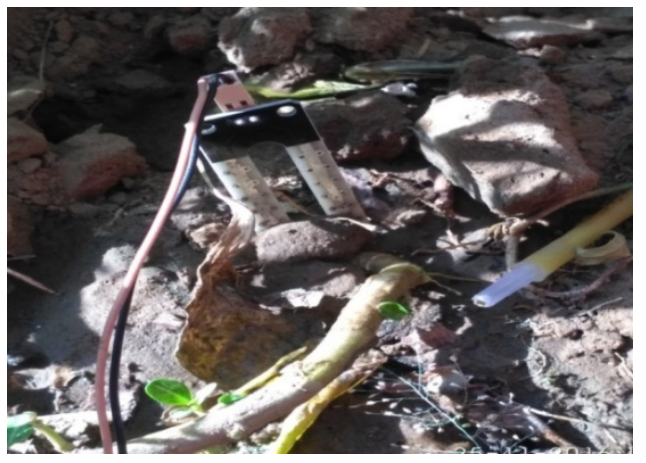

Fig-4 (i) showing actual view of farm showing drip irrigation with moisture sensor.

The whole field is divided into four sections and in each section we are inserting a soil moisture sensor as shown in fig.4 (i).By which we can take the values of whole field as each sensor showing the moisture value. The moisture value is shown according to the moisture level of each section.

When all sections are dry then moisture value is $0 \%$ as shown in fig 4(ii) and reading is display at the receiver section. Pump will be automatically ON and pumping will be done from dripper. 
When one section is wet and other are dry. Then the reading is given as shown in fig 4(iii). And the pump will remain on until the moisture value will reaches up to $100 \%$.

When all the sections are wet i.e. whole field is irrigated then moisture value is $100 \%$ as shown in fig (v). Then pump will automatically OFF.

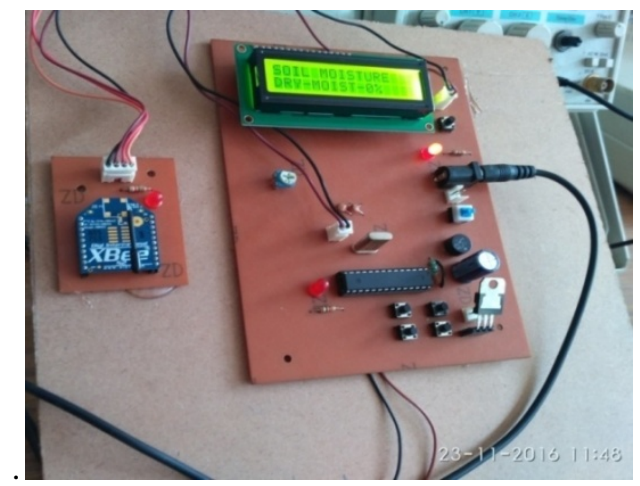

Fig-4(ii) showing moisture condition when land is totally dry

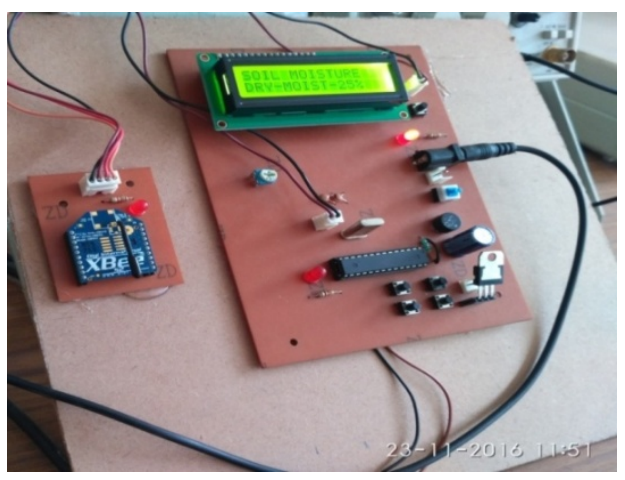

Fig-4(iii) showing moisture condition

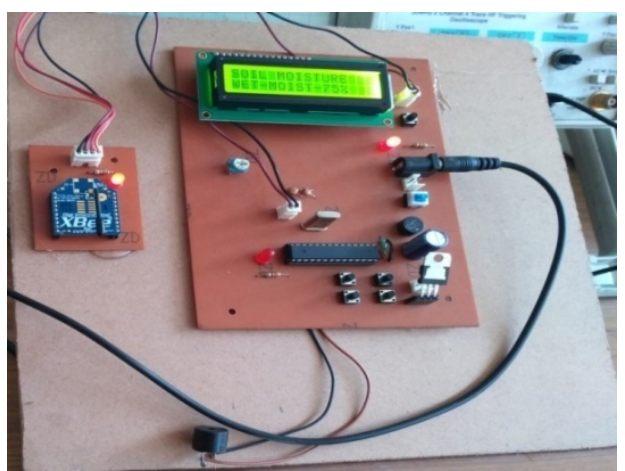

Fig-4(iv) showing moisture condition

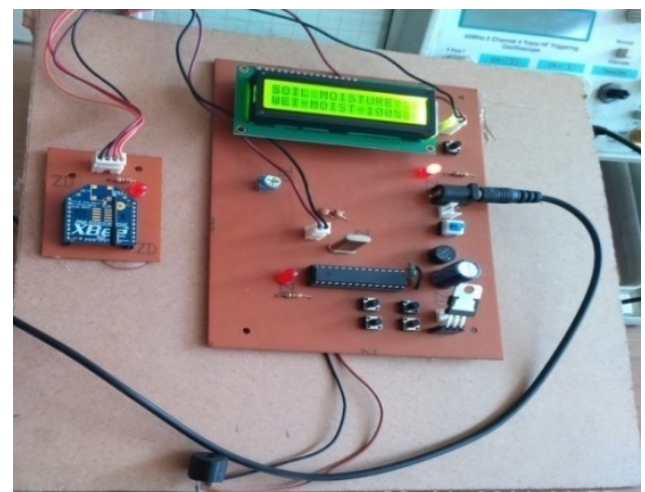

Fig-4(v) showing moisture condition when whole land is irrigated 


\section{COMPARISION TABLE:}

$\begin{array}{lll}\text { Parameters } & \text { Existing system } & \text { Proposed system } \\ \text { Water Efficiency } & \text { Water usage 100Ltrs } & \text { Water Usage 30 Ltrs } \\ & & \text { Increased Efficiency: 70\% } \\ \text { Remotely Controlled } & \text { Not controlled } & \text { Option available } \\ \text { Reduced Manpower } & \text { Manpower required } & \text { No manpower required for water }\end{array}$

Management

Power consumptionMore water required so to_ Less water required as moisture

fulfil the requirement water sensors senses the exact moisture

is freely flows and motor value so after getting $100 \%$

runs till the complete filling moisture pump automatically turns off.

of field.

Soil fertilityFertility decreases as fertilizer Increased Fertility as fertiliser need not be spread

is spread manually.over whole land but spread via dripper, only at root

stop

zone, By this technique wastage of fertilizer andfertility is also increased.

\section{CONCLUSION:}

This Automated irrigation system giving the conclusion that it is useful system as it successfully implementing the automation of irrigation and use of water efficiently by using drip irrigation. The threshold values of the sensors are continuously monitored and according to that the irrigation automation works. Finally using this system we are able to access and control the system remotely which can control the system electrical as well as the water flow.

\section{REFERENCES}

[1] A.Rhman, Z.-A. S. (2014). Wirelessly Controlled Irrigation System. iraq J Electrical and Electronic Engineering , 89-99.

[2] Anita devi, M. k. (JULY 2015). Green Wall Automation System. International Journal of Latest Trends in Engineering and Technology (IJLTET), 350-355.

[3] Atta, R. (2011). Smart Irrigation System for Wheat in Saudi Arabia using wireless sensor network technology. IJWRAE .

[4] B.VidyaSagar. ( May 2012 ). Green House Monitoring and Automatation using GSM . International Journal of Scientific and Research Publications , 1-5.

[5] Bankar, G. (April - June 2016). Automated Irrigation and fertigation system. International Journal of Electrical and Elec: April - June International Journal of Electrical and Electronics Research .

[6] Benzekri, A. M. (2007). PC-Based Automation of a Multi-Mode Control for an Irrigation System. IEEE , 310-315.

[7] Dondapati, P. P. ((August 2012)). An Automated Multi Sensored Green House Management. International Journal of Technological Exploration and Learning (IJTEL) , 21-24.

[8] Fule, C. R. (January 2014). Design and Implementation of Real Time Irrigation System using a Wireless Sensor Network. International Journal of Advance Research in Computer Science and Management Studies , 401-404.

[9] Gunturi, V. N. ( April-2013 ). Micro Controller Based Automatic Plant Irrigation System. International Journal of Advancements in Research \&Technology , 194-198.

[10] H.T.Ingale, N. (November 2012). Automated Irrigation System. International Journal of Engineering Research and Development , 5154.

[11] KaushikManju, A. R. (July 2015). Remotely controlled microcontroller based Automatic Irrigation System. International Journal of Latest Trends in Engineering and Technology (IJLTET), 269-274.

[12] Khandelwal, S. A. ( 2012). Automated Green House Management Using GMS Modem . International Journal of Computer Science and Information Technologies , 3099-3102.

[13] Kia, P. (2009). intelligent control based fuzzy logic for automation green house irrigation system in evaluation in relation to conventional system. World Applied Science Journal , 16-23.

[14] Kolhe, S. A. (June 2012). Implementation of Green House Automation using ARM7 Controller. International Journal of Computer Applications , 1-5.

[15] Kumbhar S, R. P. (March 13 - 15, 2013). Microcontroller based Controlled Irrigation System for Plantation. Proceedings of the International MultiConference of Engineers and Computer Scientists .

[16] LaxmiShabadi, N. P. (July 2014). Irrigation Control System Using Android and GSM for Efficient Use of Water and Power. International Journal of Advanced Research in Computer Science and Software Engineering , 607-611.

[17] M.K.Bhanarkar, P. (2016). Soil salinity and moisture measurement system for grapes field by wireless sensors network. Taylor and Francis .

[18] Milind, P. K. (2014). microcontroller based adaptive irrigation system using WSN for variety crops and avoidance system for better yeild. IJRET .

[19] Nainanayake, C. S. (n.d.). Effects of drip irrigation on canopy and soil temperature, leaf gas exchange, flowering and nut setting of mature coconut. Journal of the National Science Foundation of Sri Lanka 36 (1) .

[20] R., S. G. ( NOV 12 TO OCT 13 ). GREENHOUSE AUTOMATION SYSTEM USING PSOC 3. JOURNAL OF INFORMATION, KNOWLEDGE AND RESEARCH IN ELECTRONICS AND COMMUNICATION ENGINEERING , 779-784.

[21] R.suresh, S. (February 2014). GSM based Automated Irrigation Control using Raingun Irrigation System. International Journal of Advanced Research in Computer and Communication Engineering , 5654-5657.

[22] Rashid Hussian, J. S. (March 2013). Control of Irrigation Automatically By Using Wireless Sensor Network. International Journal of Soft Computing and Engineering (IJSCE), 324-328. 
[23] S.Thenmozhi, M. (February 2014). Greenhouse Management Using Embedded System and Zigbee Technology. International Journal of Advanced Research in Electrical, Electronics and Instrumentation Engineering , 7382-7389.

[24] Syed Mubarak, S. K. (MAY 2015). Automated Irrigation System using Wireless Sensor networks and GSM Module. IJARSE .

[25] V.Ramya, B. P. (September 2012). Embedded System for Automatic Irrigation of Cardamom Field using Xbee-PRO Technology. International Journal of Computer Applications , 36-43.

[26] Waykole, U. A. (2012). Green house automation system. IJECSCSE .

[27] Y.R.Dhumal, J. (May 2013). Green House Automation using Zigbee and Smart Phone. International Journal of Advanced Research in Computer Science and Software Engineering , 495-501.

\section{AUTHOR PROFILE}

MANJU KAUSHIK She has completed B.E. in 2007 in Electronics and Communication Engineering .After that she has appointed as a Lecturer in Government Polytechnic Uttawarand also completed her M.Tech degree in 2010.In 2014 she has joined the Ph.D in electronics and communication and start research in automatic irrigation system.

RAJEEV RATAN Presently he is Assistant Professor at M.V.N. University and also working as a H.O.D. of Electronics and Communication Department.He has completed his Ph.D from Thapar University and now he is the guide of many Ph.D Scholars. 